
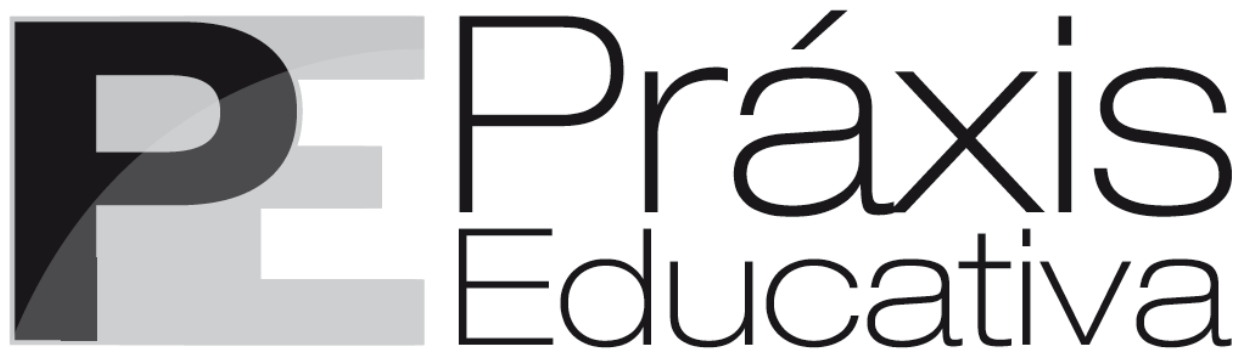

ISSN 1809-4031

eISSN 1809-4309

https://doi.org/10.5212/PraxEduc.v.15.15777.107

\title{
La escuela abandonada a evaluaciones y estándares, confinada en el managerialismo*
}

\section{The school abandoned to assessments and standards, confined to managerialism}

\section{A escola abandonada a avaliações e padrões, confinada ao gerencialismo}

Vicente Sisto ${ }^{* *}$

https:/ /orcid.org/0000-0003-4510-4041

Resumen: Las políticas educativas del Nuevo Management Público (NMP) promueven descentralización y privatización, instalando instrumentos de evaluación en función de estándares y resultados como forma de gobierno. Con ello, la acción educativa queda definida y orientada por sus indicadores. Chile ha sido considerado un caso emblemático de su puesta en práctica. Así, este artículo analiza la instalación y fortalecimiento de la lógica de la rendición de cuentas basado en estándares como eje de la acción del Estado a la hora educar, abordando además cómo este tipo de políticas responde a contextos críticos. Se realizó un análisis pragmático de los 5 cuerpos legales más relevantes promulgados entre 2008 y 2020 en Chile y un análisis descriptivo de las principales políticas educativas implementadas en el contexto crítico de la pandemia COVID19, considerando el período que va entre el 14 de marzo y el 10 de mayo de 2020. Los resultados muestran la consolidación de una política educativa que gobierna a través de evaluaciones y consecuencias, incluyendo la amenaza del cierre de escuelas. Es la Escuela la responsable por alcanzar resultados, con independencia de condiciones sociales y económicas. En un contexto de crisis, la acción del Estado se reduce a soportes débiles reivindicando la relevancia de la evaluación con consecuencias como forma de gobierno.

Palabras clave: Evaluación. Instrumentos. Nuevo Management Público. Política educativa. Rendición de cuentas.

\footnotetext{
* Este escrito ha sido posible gracias al Fondo Nacional para el Desarrollo de la Ciencia y la Tecnología (FONDECYT, Proyecto No 1191015), el Programa de Investigación Asociativa de la Agencia Nacional de Investigación y Desarrollo de Chile (ANID PIA/CIE 160009) y el Núcleo Milenio Autoridad y Asimetrías de Poder de la Iniciativa Científica Milenio.

${ }^{* *}$ Dr. en Psicología Social, Investigador Principal del Centro de Investigación para la Educación Inclusiva de la Pontificia Universidad Católica de Valparaíso. E-mail: <vicente.sisto@pucv.cl>.
}

Práxis Educativa, Ponta Grossa, v. 15, e2015777, p. 1-26, 2020 Disponível em: <https://www.revistas2.uepg.br/index.php/praxiseducativa $>$ 
La escuela abandonada a evaluaciones y estándares, confinada en el managerialismo

\begin{abstract}
The New Public Management (NMP) educational policies promote decentralization and privatization, installing performance assessment instruments based on standards and results as a form of government. With this, educational action is defined and guided by indicators. Chile has been considered an emblematic case of these politics. This article analyzes the installation and strengthening of the logic of accountability based on standards as the axis of the State's educational action and how this type of policy responds to critical contexts. We carried out a pragmatic analysis of the five most relevant legal bodies promulgated between 2008 and 2020 in Chile and a descriptive analysis of the main educational policies implemented in the critical context of the COVID19 pandemic, considering the period between March 14 and May 10, 2020. The results show the consolidation of an educational policy that governs through evaluations and consequences, including the threat of school closure. The School is responsible for achieving results, regardless of social and economic conditions. In a context of crisis, the action of the State is reduced to weak supports, claiming the relevance of the evaluation
\end{abstract} with consequences as a form of government.

Keywords: Evaluation. Instruments. New Public Management. Educational policy. Accountability.

Resumo: As políticas educacionais da Nova Gestão Pública (NMP) promovem a descentralização e a privatização, instalando instrumentos de avaliação baseados em padrões e resultados como forma de governo. Com isso, a ação educativa é definida por seus indicadores. O Chile é considerado um caso emblemático de sua implementação. Este artigo analisa a instalação e o fortalecimento da lógica da responsabilização pautada nas normas como eixo da ação do Estado ao educar em Chile, abordando também como esse tipo de política responde a contextos críticos. Foi realizada uma análise pragmática dos cinco órgãos jurídicos mais relevantes promulgados entre 2008 e 2020 no Chile e uma análise descritiva das principais políticas educacionais implementadas no contexto crítico da pandemia COVID19, considerando o período entre 14 de março e 10 de maio de 2020. Os resultados mostram a consolidação de uma política educacional que rege por meio de avaliações e consequências, incluindo a ameaça de fechamento de escolas. A Escola é responsável pela obtenção de resultados, independentemente das condições sociais e econômicas. Num contexto de crise, a ação do Estado reduz-se a fracos suportes, reivindicando a relevância da avaliação com consequências como forma de governo. Palavras-chave: Avaliação. Instrumentos. Nova Gestão Pública. Política educacional. Prestação de contas.

\title{
Introducción
}

Las políticas de rendición de cuentas (accountability) con altas consecuencias, vinculadas a financiamiento y cierre de escuelas, han sido promovidas por organismos internacionales y diversos think tanks de carácter global como el modo de "hacer trabajar" a la Escuela (BRUNS, FILMER; PATRINOS, 2011; PEREIRA, 2015; RICH, 2004; VERGER; NORMAND, 2015). Esto en el contexto del diseño e implementación de políticas del llamado Nuevo Management Público en educación (HALL; GUNTER; SERPIERI, 2015; SISTO, 2017; 2020). Si bien la investigación empírica basada en escuelas ha refutado consistentemente esta creencia (GUNTER, 2008; HALL et al., 2015; LITTLE; BARTLETT, 2010; SISTO, 2012), ésta se continúa instalando dogmáticamente como una verdad única a ser promovida en diversas naciones, incluso en contextos críticos, como el que estamos viviendo derivado de la pandemia del COVID19.

Chile ha sido uno de los países que ha seguido de modo más claro estos principios manageriales en el diseño de sus políticas educativas. Su sistema educativo se caracteriza por la descentralización de la propiedad de los 'prestadores'. Así, compiten privados con públicos (municipales y de servicios locales de educación ${ }^{1}$ ) por la captación de matrícula, y mediante ella, el financiamiento estatal bajo un mecanismo de financiamiento en la modalidad voucher de subvención a la demanda (FALABELLA,

${ }^{1}$ Dependientes del Ministerio de Educación en la modalidad que establece la Ley de Nueva Educación Pública (Ley 21.040, 2017).

Práxis Educativa, Ponta Grossa, v. 15, e2015777, p. 1-26, 2020

Disponível em: <https://www.revistas2.uepg.br/index.php/praxiseducativa $>$ 
2015; FALABELLA; DE LA VEGA, 2016; OYARZÚN; CORNEJO, 2020; SISTO; FARDELLA, 2011). En este contexto, el gobierno de la escuela se realiza fundamentalmente a través de sistemas de rendición de cuentas basados en cumplimiento de estándares de desempeño, vinculados a consecuencias, en su mayoría de carácter financiero, incluyendo el cierre de escuela (SISTO, 2017; 2019a; 2019b). Como se aprecia, la noción de rendición de cuentas va más allá de la mera rendición económica de gastos, y refiere al dar cuenta, mediante resultados en instrumentos de evaluación, del cumplimiento de lo que se espera en términos de indicadores y estándares (BRUNS et al., 2011; OZGA, 2009; WATANABE, 2007).

Considerando lo mencionado, este artículo analiza la instalación y fortalecimiento de la lógica de la rendición de cuentas basado en estándares como eje de la acción del Estado a la hora educar. Para ello, en una primera parte, se revisa la perspectiva del Nuevo Management Público y su implementación en el campo de las políticas educativas, poniendo especial atención en cómo esto ha sido realizado en Chile. Luego, se exponen algunos resultados de un análisis pragmático que incluyó los cinco cuerpos legales más relevantes en regulación educativa promulgados entre el 2008 y el 2020, que ponen su foco en el fortalecimiento de la rendición de cuentas como forma de gobierno de la Educación desde el Estado. Esto permite enmarcar un análisis descriptivo acerca de las principales políticas educativas realizadas por el Estado de Chile en tiempos de pandemia, considerando el período que va entre el 14 de marzo y el 10 de mayo de 2020. Éste muestra cómo la acción del Estado en relación al educar continúa siendo la rendición de cuentas en función de estándares, dejando a profesores y comunidades educativas obligadas a ingeniarse para trabajar en función de los estándares al evaluar.

\section{Nuevo Management y la rendición de cuentas con altas consecuencias}

Todos los días recibo reclamos de gente que quiere que el ministerio le arregle el techo de un colegio que tiene goteras, o una sala de clases que tiene el piso malo. Y yo me pregunto: ¿Por qué no hacen un bingo? ¿Por qué desde Santiago tengo que ir a arreglar el techo de un gimnasio?... Son los riesgos del asistencialismo, la gente no se hace cargo de sus problemas, sino que quiere que el resto lo haga.

Discurso del Ministro de Educación Gerardo Varela en el aniversario de Enseña Chile; 21 de julio de 2018

Este texto fue leído por el Ministro de Educación Gerardo Varela para celebrar el aniversario de la fundación Enseña Chile, fundación privada cuyo directorio está compuesto principalmente por empresarios, gerentes de empresas y dueños de escuelas privadas subvencionadas. Su propósito es llevar profesionales no pedagogos a escuelas vulnerables como profesores durante un período limitado, siguiendo el ejemplo de su par Teach for America. Las palabras del ahora exministro no son casuales. Tampoco el lugar. Éstos expresan una lógica que se ha instalado como obvia a la hora de pensar la acción pública y las políticas que la sustentan: el Nuevo Management Público ((NMP); HOOD, 1991), que ha sido fuertemente promovido por organismos internacionales (ver BRUNS; FILMER; PATRINOS, 2011; SHAH, 2005; SO et al., 2018; VEGAS; GANIMIAN, 2011, entre otros).

Tal como explican Osborne y Gaebler (1992), promotores relevantes de esta perspectiva, el Estado debe reinventarse, transformar su estructura con el fin de utilizar lo que sería el poder de la acción empresarial y la fuerza del libre mercado. Esto supone descentralizar los servicios públicos, disminuyendo fondos basales, e incorporar privados a la provisión de estos servicios, todo en el contexto de sistemas de financiamiento según resultados y compromisos de desempeño. La

Práxis Educativa, Ponta Grossa, v. 15, e2015777, p. 1-26, 2020

Disponível em: <https://www.revistas2.uepg.br/index.php/praxiseducativa $>$ 
competencia entre prestadores (públicos y privados) mejoraría la calidad de la acción pública, estimulando además a la iniciativa privada. El informe "Public services delivery" del Banco Mundial, a cargo de Shah (2005), confirma esta prescripción. Así, responsabilización por resultados, rendición de cuentas, descentralización, privatización de la provisión de servicios públicos y financiamiento condicionado a evaluaciones y resultados, toman centralidad en lo que sería una "sana gestión pública". El reciente informe "Alternative Paths to Public Financial Management and Public Sector Reform. Experiences from East Asia” (SO et al., 2018) confirma la vigencia de estos criterios.

Esto se ha materializado en el campo educativo mediante la creciente entrada de privados a la 'provisión de servicios educativos' en un contexto de mecanismos de financiamiento basados en el pago por matrícula y asistencia (subvención a la demanda) y de instalación de reformas que intensifican la rendición de cuentas en el campo de los resultados de aprendizaje y del cumplimiento de estándares de desempeño, asociando altas consecuencias. Esto supone la aplicación cenal de los instrumentos de evaluación de aprendizaje y de desempeño a profesores y directivos con el fin de garantizar la rendición de cuentas de todos los prestadores del sistema (BRUNS et al., 2011; FALABELLA; DE LA VEGA, 2016; QUARESMA; VALENZUELA, 2017; SISTO, 2012; WATANABE, 2007). Así, todos los niños de ciertos niveles deben rendir pruebas estandarizadas que evalúen su nivel de aprendizaje en determinados campos, preferentemente lenguaje y matemáticas, permitiendo comparabilidad de resultados y la elaboración de clasificaciones y rankings de escuelas. También todos los profesores del sistema deben someterse a procesos de evaluación, que, tal como se ha promovido, deben exigir y evaluar el cumplimiento de estándares de desempeño. Así, muestras de desempeño docente (videos de clases, planificaciones curriculares, entre otros) deben ser extraídos del contexto particular en el cual se ejerce el desempeño, la escuela, su comunidad, para analizar y evaluar el desempeño individual del profesor por sí mismo, lo que permite no sólo la evaluación del desempeño individual, sino que también la comparabilidad y clasificación en función de los estándares traducidos en rubricas específicas acerca de lo que se espera de un profesor en cualquier aula de clases y en cualquier comunidad (ver VEGAS; GANIMIAN, 2011). Bajo el argumento de que, de este modo se favorecería una educación de similar calidad para todos (BRUNS et al., 2011; BRUNS; LUQUE, 2014).

Tal como se aprecia, bajo las lógicas del Nuevo Management se descentraliza la provisión de lo público, en este caso la educación, incorporando privados, y controlando preferentemente mediante instrumentos de evaluación en función de estándares y resultados. Pero estos serían impotentes si no estuvieran asociados a consecuencias (BRUNS et al., 2011; CHATELAIN-PONROY et al., 2018; POLESEL; RICE; DULFER, 2013; SELBERG, 2013; VALLI; BUESE, 2007; VERBEETEN; SPEKLÉ, 2015). En efecto, desde el Nuevo Management Público, el gobierno de la educación, así como de cualquier otro campo de acción pública, debe ser por medio de instrumentos de rendición de cuentas cuyos resultados estén asociados a consecuencias. En el caso de la escuela, su cierre, castigos o incentivos; en el caso de profesores, salarios, incentivos económicos, promoción de carrera, despidos, entre otros, han sido señalados como posibles consecuencias (BRUNS et al., 2011; VEGAS; GANIMIAN, 2011). Así, los instrumentos de medición de desempeño y resultado, vinculados a consecuencias, modelan la acción pública, y con ello lo que hacen los trabajadores de lo público. Los instrumentos instalan el mapa de lo que es relevante y de lo que no es. Lo que cuenta para los instrumentos es lo que cuenta para la política. De este modo, toda acción debe quedar traducida a esta gramática cuantificada que proveen estos instrumentos de medición, imponiendo los criterios y objetivos prescritos por el diseño de la política (GAO, 2015; LE GALÈS, 2016). La heterogeneidad de prácticas locales necesarias para favorecer y sostener los procesos educativos independientemente de su contexto y de su vulnerabilidad, deben inscribirse en el lenguaje de los instrumentos de rendición

Práxis Educativa, Ponta Grossa, v. 15, e2015777, p. 1-26, 2020 
de cuentas: pruebas estandarizadas y mediciones de desempeño. Con ello, estos instrumentos, permiten por una parte visibilizar ante los niveles centrales lo que cada profesor y escuela hace en relación a lo que instala la política, facilitando comparaciones y decisiones de gasto e inversión en base a una métrica unidimensional (MILLER; O’LEARY, 2007; SISTO; ZELAYA, 2013). Pero además, actúan en el nivel local prescribiendo y moldeando los objetivos en torno a los cuales las comunidades educativas, estudiantes, profesores, apoderados, directivos deben actuar.

Pruebas estandarizadas y evaluaciones de desempeño según estándares, entre otros, logran generar medidas de desempeño que enfatizan el control y la responsabilidad por los resultados, estableciendo un rango de medidas de eficacia por las cuales individuos, unidades y organizaciones pueden ser juzgados. Son los instrumentos los que concretan al NMP en el terreno cotidiano de la escuela, interpelando actores, organizando y territorializando el campo, estableciendo, objetivos, medios, posiciones y formas de acción; cambiando el contenido y las tareas que definen al trabajo público, introduciendo nuevos regímenes de desempeño que redefinen lo que debe hacer y ser el trabajador (AGGERI; LABATUT, 2011; BAUDOT, 2014; LE GALÈS, 2010; KURUNMÄKI; MILLER, 2011; SHORE; WRIGHT, 2015; SISTO, 2004).

Autonomía, descentralización, financiamiento por matrícula y asistencia de estudiantes, y responsabilización en función de resultados medidos por instrumentos estandarizados, son parte fundamental de la concreción del Nuevo Management Público en el campo escolar. La cita del exministro Varela con la que se inicia esta sección es clara. Los problemas en las goteras del techo de la Escuela, o el piso malo de la sala de clases, no son problemas del Ministerio de Educación, son problemas de cada escuela. Cada escuela ya recibió los recursos que merece en función de su esfuerzo por conseguir matrícula y asistencia estudiantil, así como en relación a los incentivos por resultado. Lo que le corresponde es responsabilizarse con autonomía por realizar su trabajo ¿Cuál es su trabajo? Responder a los indicadores medidos por instrumentos ¿Por qué el Ministerio de Educación va a tener que hacer algo más para apoyar a la Escuela? "¿Por qué desde Santiago tengo que ir a arreglar el techo de un gimnasio?" Tal como indicó el exministro, eso es "asistencialismo, la gente no se hace cargo de sus problemas, sino que quiere que el resto lo haga”. Todo lo contrario de la responsabilización promovida por el Nuevo Management Público. No es extraño que uno de los informes más emblemáticos del Banco Mundial, en el cual promueve autonomía a la vez que rendición de cuentas en función de instrumentos de evaluación, se denomine Making Schools Work, New Evidence on Accountability Reforms (BRUNS et al., 2011). En efecto, de lo que se trata es hacer trabajar a las Escuelas, reduciendo el rol del Estado a la medición en función de estándares y resultados, y al castigo o incentivo a la Escuela y sus trabajadores (docentes, directivos), según sea el caso, lo otros es asistencialismo. Se requiere que la Escuela se haga responsable por lo que hace, y lo que hace es lo que registran los instrumentos de evaluación.

\section{La escuela bajo el Nuevo Management Público en Chile}

Chile ha sido considerado un caso emblemático de implementación de políticas educativas inspiradas en las premisas del modelo neoliberal (BELLEI; CABALIN; ORELLANA, 2014; MCEWAN; CARNOY, 2000; SISTO, 2017). Al amparo de la violencia, la dictadura de Pinochet implementó una transformación radical en el sistema educativo chileno mediante diversos cuerpos legales. A través del Decreto Ley No. 3.063, de 1979, reglamentado en 1980 mediante el decreto 13.063, se traspasó la administración de las escuelas desde el Ministerio de Educación a las municipalidades -unidades mínimas de gobierno local-; a la par, los Decretos Leyes No. 3.166 y No.

Práxis Educativa, Ponta Grossa, v. 15, e2015777, p. 1-26, 2020

Disponível em: < https://www.revistas2.uepg.br/index.php/praxiseducativa $>$ 
3.476, del mismo año, incorporaron prestadores privados de servicios educativos subvencionados estatalmente. Todos, privados subvencionados y municipales, comienzan a competir entre sí por los recursos públicos bajo un modelo de financiamiento basado en el subsidio a la demanda, conocido como Voucher, estableciendo como principio la libre elección de escuelas por parte de los apoderados (BLANCO et al., 2014; PORTALES; VAZQUEZ-HEILIG, 2014). El modelo Voucher fue conceptualizado por Milton Friedman hace ya más de 50 años, como una estrategia para incrementar la calidad educativa, y mejorar el control del gasto público mediante la incorporación de proveedores privados en competencia con los públicos (MCEWAN; CARNOY, 2000). Con ello, la competencia se realiza en la captación de matrículas, y en el aseguramiento de la asistencia de los niños, en un contexto en el cual las escuelas privadas, a pesar de estar financiadas públicamente, no están sujetas a las mismas regulaciones y exigencias legales que las municipales, permitiéndose selección de estudiantes, amplias modalidades de gestión de recursos humanos y lucro para sus propietarios.

Este modelo prontamente se hizo coherente con las recomendaciones del Banco Mundial y otros organismos internacionales, los cuales, desde fines de la década de los 80, comenzaron a promover que los servicios públicos pueden ser llevados a cabo por prestadores privados. Esto redundaría en una eficacia del gasto, promoviendo sistemas de accountability basadas en resultados según indicadores (ver, por ejemplo, SHAH, 2005). En el caso de la educación esto se concreta en la recomendación de establecer pruebas estandarizadas de medición de aprendizaje fundamentalmente, aunque no únicamente, en las áreas de lenguaje y matemática (BRUNS; FILMER; PATRINOS, 2011).

En Chile, esto ya se había concretado mediante el Sistema de Medición de la Calidad Educativa (SIMCE) que comienza a ser implementado en la década de los ochenta, pero que sólo tenía un fin diagnóstico. Por ello, al llegar la democracia, en los noventa, este modelo de provisión de servicios educativos no fue transformado. La atmósfera producida por las crecientes recomendaciones de los organismos internacionales justificará no sólo la permanencia de este modelo, sino su perfeccionamiento (ASSAÉL et al., 2011; BLANCO et al., 2014; SISTO; MONTECINOS; AHUMADA, 2013). Por consiguiente, Chile ha sido considerado un caso extremo de políticas centradas en la provisión privada de servicios educativos financiados por el Estado, bajo un sistema regulador basado en la rendición de cuentas de altas consecuencias (BELLEI et al., 2014; CANALS, 2016; COX; MECKES, 2016; LÓPEZ et al., 2020; SISTO, 2019a; VERGER, 2012).

Sin embargo, a pesar de ser considerado como un caso ejemplar de políticas educativas realizadas, según los mandatos de la nueva gobernanza pública y del llamado New Public Management (ASSAÉL et al., 2011; CANALS, 2016; MIZALA; SCHNEIDER, 2019; MONTECINOS; SISTO; AHUMADA, 2010; SISTO; FARDELLA, 2011), durante la década del 2000 comenzaron a proliferar diversos diagnósticos en torno a que este sistema no estaba generando los resultados educativos esperados. A la vez, sí estaba generando una cada vez mayor segregación escolar y mayor brecha entre los estudiantes más pobres y los más aventajados (MIZALA; SCHNEIDER, 2019; QUARESMA; VALENZUELA, 2017). Esto cobró especial realce en el año 2006, cuando se inició una de las mayores huelgas estudiantiles del país que involucró a la casi totalidad de escuelas y liceos municipales y privados subvencionados del país. Este movimiento fue conocido como "La Revolución Pingüina", haciendo referencia al uniforme blanco y negro que utilizan los estudiantes del sistema escolar chileno participando la mayor parte de los estudiantes secundarios y de niveles superiores de la educación primaria de Chile (ASSAÉL et al., 2011; VILLALOBOS; QUARESMA, 2015). Es en este contexto de críticas provenientes de organismos internacionales, expertos y ciudadanía, que emerge la Ley de Subvención Escolar Preferencial (Ley No. 20.248, más conocida como Ley SEP, por su abreviatura en

Práxis Educativa, Ponta Grossa, v. 15, e2015777, p. 1-26, 2020 
español) como una de las principales reformas implementadas en los últimos años con el fin de perfeccionar el sistema educativo chileno, orientada a mejorar la calidad educativa que reciben sobre todo los niños y niñas más pobres de Chile.

Si bien las críticas que caracterizaron al movimiento estudiantil se dirigieron al corazón de la política, cuestionando la descentralización con proliferación de prestadores privados, el mecanismo de financiamiento y las pruebas estandarizadas, la Ley, no cambió nada de eso, por el contrario, lo reforzó. Las protestas estudiantiles sirvieron como oportunidad para perfeccionar el modelo según las recomendaciones que, por aquel entonces, instalaban los organismos internacionales y think tanks en orden de que la mejora escolar podría ser alcanzada fortaleciendo los mecanismos de rendición de cuentas, pruebas estandarizadas, evaluaciones de desempeño según estándares, reforzando las consecuencias asociadas (ver ASSAÉL et al., 2014; SISTO, 2019b). A partir de ello, las siguientes reformas continuaron radicalizando esta lógica, siguiendo los preceptos actuales del Nuevo Management Público.

A continuación, se da cuenta de los resultados de dos análisis interrelacionados: primero, el de las políticas que han fortalecido el gobierno de la Escuela por medio de evaluaciones y estándares, centrándonos en el período 2006-2020, y, segundo, el de cómo esta política educativa se comporta frente a un evento crítico que afecta a la Educación como es la pandemia COVID19. Esta suerte de caso extremo permite presentar de forma clara cómo estos modos de gobierno de lo público posicionan a los actores, particularmente al nivel central de la política y a la escuela, prescribiendo responsabilidades y formas de acción.

\section{Método}

\section{Muestra y producción de datos}

Para el primer estudio se consideraron la totalidad de leyes desarrolladas desde el año 2006 hasta el 2020. Se escoge el 2006, ya que, durante ese período, posterior a la movilización de estudiantes secundarios, se reforzó la lógica de la rendición de cuentas con altas consecuencias como la forma de gobierno de la educación en el Chile contemporáneo. De estas leyes, seis resaltan tanto por su centralidad en la estructuración del sistema educativo, como por instalar al centro de éste a la evaluación según resultados y estándares, constituyendo el corpus del primer estudio:

- Ley de Subvención Escolar Preferencial (SEP) (Ley No. 20.248, promulgada el 2008),

- Ley General de Educación (Ley No. 20.370, promulgada el 2009),

- Ley que Crea el Sistema de Aseguramiento de Calidad (Ley No. 20.529, promulgada el 2011),

- Ley de Carrera Docente (Ley No. 20.903, promulgada el 2016), y

- Ley de Nueva Educación Pública (Ley No. 21.040, promulgada el 2017).

El segundo estudio se sitúa en el contexto de la pandemia COVID19 y considera más de 30 comunicaciones públicas emitidas por el Ministerio de Educación desde el cierre físico de las Escuelas, ocurrido en Chile el 14 de marzo de 2020, hasta el 20 de mayo del mismo año, momento de cierre de

Práxis Educativa, Ponta Grossa, v. 15, e2015777, p. 1-26, 2020

Disponível em: < https://www.revistas2.uepg.br/index.php/praxiseducativa $>$ 
este artículo. El corpus analizado, escogido mediante un muestro intencional, incluye discursos, cartas públicas y otros comunicados del Ministro de Educación y otras autoridades en las que se dan instrucciones y orientaciones haciendo referencia clara a la acción de la Escuela en contexto de cierre físico por pandemia.

\section{Análisis}

Cada corpus fue abordado mediante un análisis pragmático, siguiendo la propuesta de Prior (2008 y 2016), en cuanto a que los cuerpos legales, comunicados y otros textos de carácter regulatorio, moldean formas de acción, interpelan actores y establecen un sentido para la política, es decir, los documentos actúan. Por lo tanto, el análisis consiste en establecer la acción que realizan los documentos legales, comunicados, entre otros, prescribiendo objetivos, posiciones para los actores, responsabilidades, formas de acción y mandatos para un campo de acción pública. Este análisis fue complementado con algunas herramientas propias del análisis del discurso, tal como ha sido por el grupo de Discurso y Retórica de Loughborough (ÍNIGUEZ, 2006; POT'TER; WETHERELL, 1987), caracterizado por su orientación pragmática y retórica. Particularmente, se ocuparon como herramientas la noción de repertorio interpretativo, en tanto "sistemas de términos usados recurrentemente para caracterizar y evaluar acciones, eventos y otros fenómenos" (POTTER; WETHERELL 1987, p. 149) y de posicionamiento de sujeto (KERR; CUNNINGHAM-BURLEY; TUTTON, 2007; WETHERELL, 2007).

Siguiendo a Kurunmäki, Mennicken y Miller (2016) y a Le Galès (2016), se puso especial énfasis en los procedimientos y mecanismos regulatorios que emergen. En un contexto en el cual se ha promovido la prestación privada de servicios públicos, las políticas públicas ya no están organizadas al interior de un sector demarcado o claramente estructurado, como lo fue el Estado (LE GALÈS, 2016). Por ello, la gobernanza pública responde más bien a un Estado que regula la acción de otros, que son quienes realizan finalmente la acción pública (HOLZINGER; SCHMIDT, 2015). De ahí la relevancia que adquieren los cuerpos legales, instrucciones y otras comunicaciones, en cuanto establecen en términos prácticos lo que es la política pública y lo que es lugar y responsabilidad de cada uno en realizarla. En coherencia con ello, se deben abordar los comunicados, instrucción, normas y aspectos procedimentales de la política como el modo mediante el cual actúa y se concreta el Estado (HENMAN, 2016; KURUNMÄKI; MENNICKEN; MILLER, 2016; LE GALES, 2016).

\section{Resultados}

Los resultados que se presentan son parte de un programa de investigación más amplio en políticas y prácticas de gestión en el ámbito educativo en Chile2, algunos de estos análisis ya han sido informados en diversas publicaciones, abordando la construcción de estas leyes, sus instrumentos, y su puesta en práctica (ver SISTO, 2018; 2019a; 2019b; SISTO; FARDELLA, 2014; RAMÍREZ; BALERIOLA; SISTO, 2019, entre otros).

\footnotetext{
${ }^{2}$ Línea 5 del Centro de Investigación para la Educación Inclusiva (Centro PIA-CONICYT CIE 160009).
} 


\section{Evaluaciones y estándares como forma de gobierno: Su materialización en los cuerpos legales}

La instalación de la rendición de cuentas (accountability) basada en evaluaciones estándares en el centro de la política educativa, algo que hasta ese momento no era tan evidente en las normativas previas. En esto fueron fundamentales la Ley de Subvención Escolar Preferencial (SEP) (Ley No. 20.248, promulgada el 2008), la Ley General de Educación (Ley No. 20.370, promulgada el 2009), y la Ley que Crea el Sistema de Aseguramiento de Calidad (Ley No. 20.529, promulgada el 2011), tal como mostraremos a continuación.

La Ley de Subvención Escolar Preferencial (SEP) (Ley No. 20.248, promulgada el 2008), es la primera que instala al cumplimiento de estándares de aprendizaje, verificado mediante resultados de instrumentos al centro del trabajo educativo de la Escuela. Siguiendo las recomendaciones de organismos internacionales en torno a la necesidad de generar mayores soportes focalizados a la educación, sobre todo de los más pobres y disminuir la segregación (ver informe OECD, 2004), esta ley crea una subvención preferencial por estudiante vulnerable, según la evaluación económica que realiza la Junta Nacional de Auxilio Escolar y Becas (JUNAEB) del Ministerio de Educación. Para acceder a ella, el propietario del establecimiento, conocido como sostenedor, sea público -municipioo privado, debe firmar el "Convenio de Igualdad de Oportunidades y Excelencia Educativa". Con ello, la escuela se compromete a participar de un sistema de evaluación, clasificación, incentivos y sanciones, ligados al rendimiento de los estudiantes en la prueba estandarizada SIMCE (Sistema de Medición de la Calidad de la Educación) en las asignaturas de lenguaje, matemáticas, ciencias naturales y ciencias sociales. Este desempeño representa el $70 \%$ de la clasificación que obtendrá la escuela. Para el 30\% restante se consideran otros indicadores complementarios, que incluyen los resultados de las evaluaciones de docentes (en el caso de escuelas públicas), las tasas de progresión y retención y mejoramiento escolar (condiciones de trabajo, cumplimiento de normas), iniciativas de innovación e integración con la comunidad, entre otros (Artículo 7). En función de estos resultados, las escuelas son clasificadas en orden decreciente como "autónomas", "emergentes" y "en recuperación" (Artículo 9) debiendo desarrollar un Plan de Mejoramiento que incluye metas específicas a alcanzar en el SIMCE (Artículos 8 y 9). Estas metas de rendimiento vienen prefijadas por el Ministerio de Educación, siendo especialmente exigentes para las escuelas peor evaluadas: las emergentes y en recuperación. La Ley, además, señala que los procesos de asesoría pueden ser asumidos por consultoras privadas, a las que denomina "Asistencia Técnica Educativa" (ATE; Artículos 8, 30, entre otros). Para el caso de las escuelas 'en recuperación' es obligatorio que el diagnóstico, el diseño del plan de mejoramiento y su ejecución deben ser asesorados por una ATE, para lo cual se deben invertir los fondos de la subvención preferencial. Un elemento clave de esta Ley refiere a la imposición de la amenaza de cierre de aquellas escuelas que se han mantenido en la categoría de "en recuperación” por un período de cuatro años.

Art 28. Concluido el plazo a que se refiere el $\mathrm{N}^{\circ}$ 1) del artículo 26, el establecimiento educacional en Recuperación deberá alcanzar los resultados educativos que permitan ordenarlo en una categoría superior, de acuerdo a los mecanismos establecidos en la ley $\mathrm{N}^{\circ}$ $20.529[\ldots]$. En el caso de no lograrse los resultados educativos señalados en el inciso primero, los establecimientos estarán afectos al mecanismo de revocación del reconocimiento oficial que se establece en los artículos 30 y 31 de la ley que crea el Sistema Nacional de Aseguramiento de la Calidad de la Educación.

Tal como Assaél et al. (2014) y Oyarzún-Maldonado y Soto-González (2018) han indicado, esta política responde al llamado de organismos internacionales acerca de la importancia de focalizar el gasto social en aquellos grupos más vulnerables socioeconómicamente. De este modo, la subvención preferencial se constituye en un aporte compensatorio del Estado orientado a corregir la desigual

Práxis Educativa, Ponta Grossa, v. 15, e2015777, p. 1-26, 2020 
La escuela abandonada a evaluaciones y estándares, confinada en el managerialismo

distribución de oportunidades educativas, siguiendo el diagnóstico y recomendaciones que ya había realizado la OCDE acerca de Chile (OCDE, 2004). Así también, esta ley materializa los principios de transferencia condicionada de fondos a prestadores descentralizados de servicios públicos. Estableciendo ciertos límites de probidad administrativa, los prestadores tienen cierta autonomía en la administración de recursos, a cambio de lo cual deben responder generando los resultados comprometidos según los instrumentos y sistemas de rendición de cuentas establecidos (ver SHAH, 2005).

Los establecimientos están llamados a tomar decisiones estratégicamente y establecer sus planes de mejoramiento, si bien con cierta autonomía, siempre orientados a lograr los resultados esperados, en este caso en test SIMCE, haciéndose cargo de las consecuencias de estos (MURNANE; PAGE; VEGAS, 2009). Siguiendo las recomendaciones de los organismos internacionales, son las consecuencias las que aseguran los procesos de responsabilización, especialmente para las Escuelas. Tal como han señalado los informes del Banco Mundial a cargo de Bruns, Filmer y Patrinos (2011), y Bruns y Luque (2014), las altas consecuencias movilizan a las escuelas, las "hacen trabajar". Así, en Chile, la amenaza de cierre instalada por la Ley SEP se transforma en uno de los mecanismos más importantes de la política, la que se suma a la amenaza constante de pérdida de matrícula propia de un sistema de libre competencia entre escuelas, como el chileno.

Esta lógica se refuerza mediante la Ley General de Educación (Ley No. 20.370) promulgada en el 2009 (CHILE, 2009). Esta es una Ley Orgánica que reemplaza a la anterior Ley Orgánica Constitucional en Educación (LOCE) de 1990 y tiene como fin estructurar en su conjunto el sistema educativo. Es la piedra angular del sistema. Uno de los elementos que destaca refiere a que, en su definición del sistema educativo, prontamente indica como principio la calidad, elemento que no estaba en la LOCE de 1990. Es importante atender a la definición específica de calidad que se da:

Art 3. El sistema educativo chileno se construye sobre la base de los derechos garantizados en la Constitución, así como en los tratados internacionales ratificados por Chile y que se encuentren vigentes y, en especial, del derecho a la educación y la libertad de enseñanza. Se inspira, además, en los siguientes principios:

a) Universalidad y educación permanente. La educación debe estar al alcance de todas las personas a lo largo de toda la vida.

b) Calidad de la educación. La educación debe propender a asegurar que todos los alumnos y alumnas, independientemente de sus condiciones y circunstancias, alcancen los objetivos generales y los estándares de aprendizaje que se definan en la forma que establezca la ley [...]. (CHILE, 2009, p. 2)

Como podemos apreciar calidad queda definido por el asegurar que alumnas y alumnos alcancen los objetivos generales y estándares de aprendizaje. La noción de aseguramiento ya da cuenta de la presencia clara de la lógica del Nuevo Management Público en el corazón de la estructuración del sistema educativo chileno. El deber del Estado más que proveer, asegura, y lo que asegura es cumplimiento.

El artículo 7 materializa esta noción de asegurar a través de la instalación de una entidad orientada a ello. La Agencia de Calidad de la Educación establece que:

Art. 7. El Ministerio de Educación y la Agencia de Calidad de la Educación velarán, de conformidad a la ley, y en el ámbito de sus competencias, por la evaluación continua y periódica del sistema educativo, a fin de contribuir a mejorar la calidad de la educación.

Para ello, la Agencia de Calidad de la Educación evaluará los logros de aprendizaje de los alumnos y el desempeño de los establecimientos educacionales en base a estándares

Práxis Educativa, Ponta Grossa, v. 15, e2015777, p. 1-26, 2020

Disponível em: <https://www.revistas2.uepg.br/index.php/praxiseducativa $>$ 
indicativos.

La evaluación de los alumnos deberá incluir indicadores que permitan efectuar una evaluación conforme a criterios objetivos y transparentes.

La evaluación de los profesionales de la educación se efectuará de conformidad a la ley [...]. (CHILE, 2009, p. 3)

Este artículo da cuenta que asegurar calidad es evaluar. Evaluación continua y periódica como modo de mejorar a la Educación: evaluación de logros de aprendizaje de los alumnos, de desempeño de los establecimientos en base a estándares, evaluación de los profesionales de la educación. Esta centralidad de la evaluación en el gobierno de la educación queda reforzada en el siguiente artículo.

Art. 37. Le corresponderá a la Agencia de Calidad de la Educación diseñar e implementar el sistema nacional de evaluación de logros de aprendizaje. Esta medición verificará el grado de cumplimiento de los objetivos generales a través de la medición de estándares de aprendizaje referidos a las bases curriculares nacionales de educación básica y media. La Agencia deberá contar con instrumentos válidos y confiables para dichas evaluaciones, que se apliquen en forma periódica a lo menos en un curso, tanto en el nivel de educación básica como en el de educación media, e informar los resultados obtenidos. Estas mediciones deberán informar sobre la calidad y equidad en el logro de los aprendizajes a nivel nacional [...].

Las evaluaciones nacionales periódicas serán obligatorias y a ellas deberán someterse todos los establecimientos educacionales de enseñanza regular del país.

La Agencia de Calidad de la Educación deberá informar públicamente los resultados obtenidos a nivel nacional y por cada establecimiento educacional evaluado [...]. (CHILE, 2009, p. 14)

Este artículo no sólo da cuenta de la evaluación en cuanto medición de estándares de aprendizaje, sino que también instala la obligatoriedad de su realización periódica y su aplicación a todos los establecimientos.

De esta forma, la Ley General de Educación del 2009 instala lo que la LOCE de 1990, última ley aprobada por Pinochet, no había hecho: poner al evaluar al centro de la acción del Estado, como modo de movilizar a actores, diversos, que dan vida a la educación en el nivel escolar. Gobernar la educación es evaluar.

La tercera Ley que consolida este Estado evaluador es la Ley que Crea el Sistema de Aseguramiento de Calidad (CHILE, Ley No. 20.529) del 2011. El artículo 2o. indica lo siguiente:

Art. 2. El Sistema actuará sobre la educación formal, de acuerdo a los objetivos generales y sus respectivas bases curriculares señalados en la ley No. 20.370, General de Educación, y operará mediante un conjunto de políticas, estándares, indicadores, evaluaciones, información pública y mecanismos de apoyo y fiscalización a los establecimientos, para lograr la mejora continua de los aprendizajes de los alumnos, fomentando las capacidades de los establecimientos y sus cuerpos directivos, docentes y asistentes de la educación. Asimismo, el Sistema contemplará los recursos necesarios para su adecuado funcionamiento.

El Sistema comprenderá, entre otros, procesos de autoevaluación, evaluación externa, inspección, pruebas externas de carácter censal y, cuando corresponda, apoyo técnico pedagógico en la elaboración e implementación de planes de mejora educativa a nivel de establecimientos que permitan desarrollar sus fortalezas y superar sus debilidades.

El Sistema contemplará, además, la rendición de cuentas de los diversos actores e instituciones del sistema escolar y, en particular, de los establecimientos educacionales.

Asimismo, incluirá las consecuencias jurídicas que se deriven de la aplicación de los instrumentos a que se refieren los incisos anteriores y el régimen de sanciones que indica la ley. (CHILE, 2011, p. 1).

Práxis Educativa, Ponta Grossa, v. 15, e2015777, p. 1-26, 2020

Disponível em: <https://www.revistas2.uepg.br/index.php/praxiseducativa> 
La Ley de Aseguramiento de la Calidad materializa varios de los preceptos ya instalados por la Ley General de Educación el 2009. Tal como indica opera por medio de estándares, indicadores, evaluaciones, entre otros, incluyendo consecuencias derivadas de los resultados de la aplicación de instrumentos. Esto define también el rol de la Agencia a cargo de operar esta Ley

Art 10. El objeto de la Agencia será evaluar y orientar el sistema educativo para que éste propenda al mejoramiento de la calidad y equidad de las oportunidades educativas, considerando las particularidades de los distintos niveles y modalidades educativas.

Para el cumplimiento integral de dicho objeto tendrá las siguientes funciones:

a) Evaluar los logros de aprendizaje de los alumnos de acuerdo al grado de cumplimiento de los estándares, referidos a los objetivos generales señalados en la ley y sus respectivas bases curriculares por medio de instrumentos y procedimientos de medición estandarizados y externos a los establecimientos. Asimismo, deberá evaluar el grado de cumplimiento de los otros indicadores de calidad educativa.

b) Realizar evaluaciones del desempeño de los establecimientos educacionales y sus sostenedores en base a los estándares indicativos de desempeño.

c) Ordenar los establecimientos educacionales en función de las mediciones de los resultados de aprendizaje y de los otros indicadores de calidad educativa con la finalidad, entre otras, de identificar, cuando corresponda, las necesidades de apoyo. (CHILE, 2011, p. 4).

Evaluar logros de aprendizaje de estudiantes mediante instrumentos estandarizados externos a los establecimientos, evaluar desempeño de los establecimientos mediante estándares indicativos, ordenar a través de un sistema clasificatorio, son todas tareas mediante las cuales supuestamente se hace educación de calidad. El ordenamiento genera categoría, que quedan establecidas en el Artículo 17:

Art. 17. [...] Para efectos de la ordenación existirán las siguientes categorías de establecimientos, según los resultados de aprendizaje de los alumnos, en función del grado de cumplimiento de los estándares de aprendizaje y el grado de cumplimiento de los otros indicadores de calidad educativa con la finalidad, entre otras, de identificar, cuando corresponda, las necesidades de apoyo:

a) Establecimientos Educacionales de Desempeño Alto.

b) Establecimientos Educacionales de Desempeño Medio.

c) Establecimientos Educacionales de Desempeño Medio-Bajo.

d) Establecimientos Educacionales de Desempeño Insuficiente. (CHILE, 2011, p. 7).

Cabe señalar que el cumplimiento de los estándares de aprendizaje (resultados de los estudiantes en prueba SIMCE), equivale al 67\% al menos, según establece el Art. 18.

Este ordenamiento sigue los principios ya establecidos previamente por la Ley SEP (CHILE, 2008), resultando fundamental, pues genera consecuencias, desde mayor autonomía en el uso de recursos, hasta el cierre de escuelas, como lo establece el Art. 31:

Art. 31. Si después de cuatro años, contados desde la comunicación señalada en el artículo 28 , y con excepción de lo previsto en el inciso segundo del artículo 29, el establecimiento educacional se mantiene, considerando como único factor el grado de cumplimiento de los estándares de aprendizaje, en la categoría de Desempeño Insuficiente, la Agencia, dentro del primer semestre, certificará dicha circunstancia. Con el solo mérito del certificado el establecimiento educacional perderá, de pleno derecho, el reconocimiento oficial al término del respectivo año escolar (CHILE, 2011, p. 10).

Tal como se puede apreciar, después de cuatro años en la categoría de insuficiente, es decir, con bajos puntajes en la prueba de evaluación SIMCE, considerando que pondera el 67\%, el

Práxis Educativa, Ponta Grossa, v. 15, e2015777, p. 1-26, 2020

Disponível em: <https://www.revistas2.uepg.br/index.php/praxiseducativa> 
establecimiento debe ser cerrado. He aquí parte de las consecuencias que dan valor al sistema de evaluación, y por el cual se movilizan establecimientos, apoderados, profesores y estudiantes. Es así que el Estado 'activa' a la Escuela para que persiga los resultados, haciéndose responsable por ello. El cierre de escuelas en función de su desempeño en los tests estandarizados es una muestra de cómo las políticas de rendición de cuentas de altas consecuencias interpelan a las escuelas. Sus promotores han insistido en que este tipo de medidas 'hace trabajar a las escuelas' (ver BRUNS, FILMER \& PATRINOS, 2011).

\section{La escuela abandonada, confinada en el managerialismo}

Desde inicios del año 2020, el Corona Virus (COVID19, Sars-Cov-2) ha impactado a nivel mundial la vida cotidiana, produciendo cuarentenas o confinamientos en la mayor parte del mundo. Chile no ha estado exento a ello. El sábado 14 de marzo a las 11.00 h AM, en conferencia de prensa, el gobierno señaló que no se suspenderían las clases. Sin embargo, al día siguiente fueron suspendidas gracias a la presión de las y los alcaldes, que a su vez, contaban con la presión de las comunidades escolares. Fue así que, desde el 16 de marzo del 2020 y al menos hasta el envío de este artículo, a fines de mayo, las escuelas están cerradas, suspendiéndose toda actividad presencial.

La coyuntura resulta significativa. No sólo se trata de meses sin encuentros ni actividades presenciales y confinamiento en los hogares, además, en paralelo, van aumentando los contagios y las muertes, tocando al propio sistema escolar. A ello se suman las dificultades para llevar el proceso educativo a distancia, muchas veces con baja o nula conectividad a internet, con accesos limitados a equipos, normalmente teléfonos celulares. En este contexto ¿cómo puede desarrollarse un proceso educativo propiamente tal, que valga la pena en este contexto?

El Ministerio de Educación chileno desplegó diversas acciones desde el mismo domingo 15 de marzo. Primeramente, subió la guía Orientaciones Mineduc Covid-19 al sitio web del Ministerio. En esta se indicaban procedimientos e instrucciones para los distintos actores de la comunidad:

El Ministerio dispondrá de un programa de aprendizaje remoto a través de la plataforma aprendoenlinea.mineduc.cl con recursos educativos alineados al currículum escolar de $1^{\circ}$ básico a $4^{\circ}$ medio. La plataforma está disponible desde hoy para todos los estudiantes del país y contempla:

a) Uso guiado del texto escolar para todos los estudiantes desde $1^{\circ}$ básico hasta $4^{\circ}$ medio en Lenguaje y Matemática, que estará acompañado de evaluaciones en línea para que los estudiantes demuestren lo aprendido y permita monitoreo de sus docentes.

b) Textos escolares digitales de todas las asignaturas (75).

c) Material pedagógico complementario que permite a los estudiantes profundizar su educación en todas las asignaturas y niveles. Aquí se podrá encontrar material interactivo, audiovisual, cursos de profundización y acceso a cientos de libros.

d) Orientaciones para docentes y equipos directivos para guiar el aprendizaje a distancia con sus estudiantes, a través del uso de plataformas de comunicación digitales ...

(CHILE, 2020. Orientaciones Mineduc Covid-19. 15/03/2020)

Ya durante la semana, el propio Ministro difundía la estrategia a realizar durante la pandemia:

Esta suspensión no son vacaciones, y como no son vacaciones hemos dispuesto una serie de recursos para que los alumnos, los jóvenes puedan seguir estudiando desde sus casas [...]. Aquí lo importante es que los establecimientos organicen bien su trabajo [...]. Es muy importante que los docentes se comprometan con que esta suspensión no puede afectar en demasía los aprendizajes de los niños y jóvenes y en ese sentido lo que le hemos pedido a

Práxis Educativa, Ponta Grossa, v. 15, e2015777, p. 1-26, 2020

Disponível em: <https://www.revistas2.uepg.br/index.php/praxiseducativa $>$ 
cada sostenedor [propietario], a cada director de establecimiento, que coordine sus equipos para que de la mejor manera posible esto pueda ser llevado adelante [...]. Hay que confiar mucho en que nuestros alumnos, los niños, van a estar en condiciones de seguir estas guías pedagógicas y para ello trasmitirles la importancia de que esto no son vacaciones de que tienen recursos disponibles, que los utilicen que los aprovechen, y en la noche preguntarles cómo aprovechaste el día cómo ordenaste tu jornada, de alguna manera apuntar a que sigan la rutina escolar y la trasladen al hogar. (MINISTRO RAÚL FIGUEROA, Canal 13, 17/03/2020)

El ministro refuerza la idea de que este período debe ser de trabajo para los estudiantes: 'no son vacaciones'. Llama la atención esa dualidad que se establece entre escuela y vacaciones, obviando el proceso de confinamiento y pandemia, con las consecuencias sociales y psicológicas que eso supone. El deber del estudiante es trabajar en sus aprendizajes: Hay que confiar mucho en que nuestros alumnos, los niños, van a estar en condiciones de seguir estas guías pedagógicas. El estudiante es interpelado como responsable de seguir estas guías día a día. El apoderado es responsable de asegurar, mediante alguna clase de chequeo, ese trabajo del estudiante: en la noche preguntarles cómo aprovechaste el día cómo ordenaste tu jornada. $\mathrm{Y}$ los profesores y directivos comprometidos y responsables de que esta suspensión no puede afectar en demasía los aprendizajes de los niños y jóvenes. Por ello, profesores y directivos son señalados como quienes pueden llevar adelante esto de la mejor manera posible.

La plataforma aprendoenlinea.mineduc.cl se constituye de guías en $p d f$ que deben ser descargadas por estudiantes y/o apoderados para trabajar autónomamente. Están ordenadas por nivel educacional y área de conocimiento. Así se espera que la o el estudiante pueda llevar adelante su proceso educativo.

A continuación se ofrecen dos imágenes de las guías:

Práxis Educativa, Ponta Grossa, v. 15, e2015777, p. 1-26, 2020

Disponível em: <https://www.revistas2.uepg.br/index.php/praxiseducativa $>$ 
Vicente Sisto

Figura 1 - Clase 2, $4^{\circ}$ básico, Lenguaje

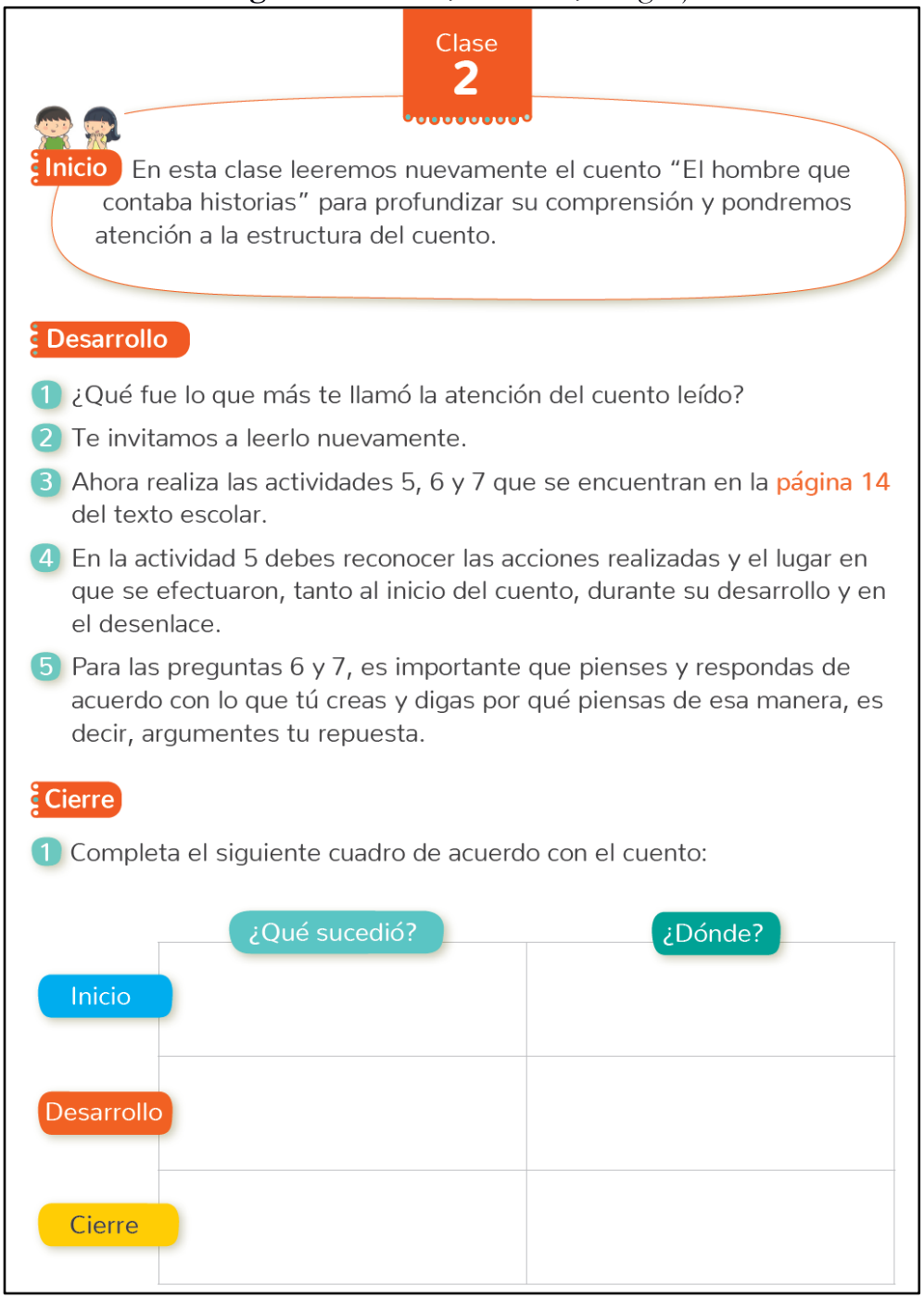

Fuente: Aprendo en Línea https://www.curriculumnacional.cl/estudiante/621/articles-144787_recurso_pdf.pdf (imagen descargada el 10 de Mayo de 2020).

Práxis Educativa, Ponta Grossa, v. 15, e2015777, p. 1-26, 2020 Disponível em: <https://www.revistas2.uepg.br/index.php/praxiseducativa> 
Figura 2 - Unidad 2, Asignatura Tecnología, $2^{\circ}$ Medio

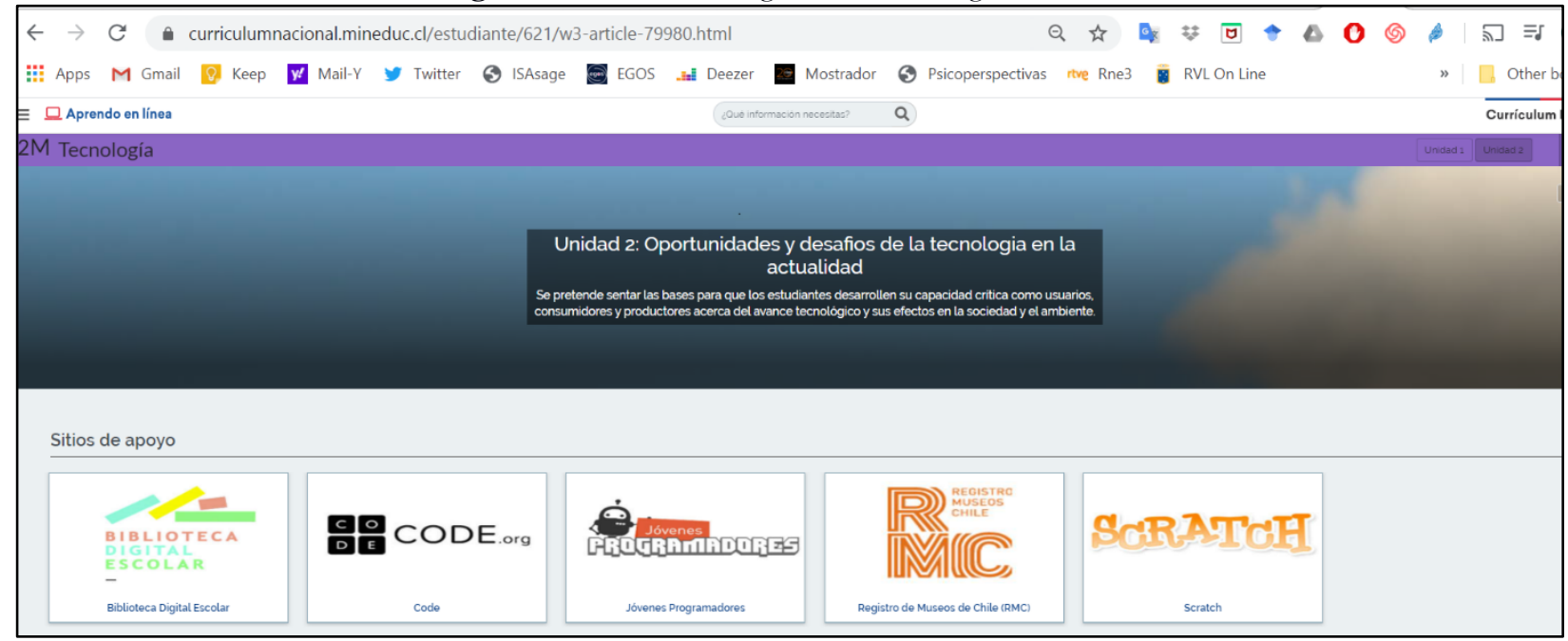

Fuente: Aprendo en Línea

https://www.curriculumnacional.cl/estudiantes/Educacion-General/Tecnologia/Tecnologia-2-medio/79980:Unidad-2Oportunidades-y-desafios-de-la-tecnologia-en-la-actualidad (imagen descargada el 10 de Mayo de 2020).

Tal como se puede apreciar en el caso de $4^{\circ}$ básico, la guía más bien da instrucciones para trabajar con el texto escolar oficial, resultando débil en el ejercicio de andamiaje de procesos de aprendizaje. La Imagen 2, refiere a la $2^{\circ}$ Unidad de la Asignatura Tecnología para segundo medio. Lo único que entrega el sitio web es el objetivo de la unidad y 5 links, sin siquiera una orientación al respecto. Todo queda a cargo del estudiante, del apoderado y lo que pueda hacer la escuela y los profesores en un contexto en que la conectivas de las y los estudiantes es limitada.

En este contexto, el miércoles 25 de marzo se decide adelantar las vacaciones de invierno. Esta se ejecutó a través de resoluciones emitidas por cada Secretaria Ministerial Regional (SEREMI). Un elemento que llamó la atención de estas resoluciones es que nuevamente daban cuenta claramente de la responsabilidad acerca de los procesos de aprendizaje: Los sostenedores y directivos de establecimientos educacionales deben asegurar el cumplimiento del plan de estudio y la totalidad de las semanas de clases que les corresponde desarrollar de acuerdo a este acto administrativo. (RESOLUCIÓN EXENTA Nº 675 27/03/2020 SEREMI de Educación Región Metropolitana, p. 4)

Adicionalmente, el día 27 de abril, se habilitó un canal de televisión en señal UHF, por lo que no es accesible ampliamente, que emite además por internet (TV Educa Chile ${ }^{3}$ ), el cual se compone de una serie de producciones animadas nacionales, junto con la serie Plaza Sésamo, y otros, tal como se puede apreciar en la imagen 3 (programación correspondiente al martes 28 de abril).

\footnotetext{
${ }^{3}$ https://www.tvn.cl/tveducachile/
} 
Figura 3 - Programación TV Educa Chile, 28 de abril de 2020

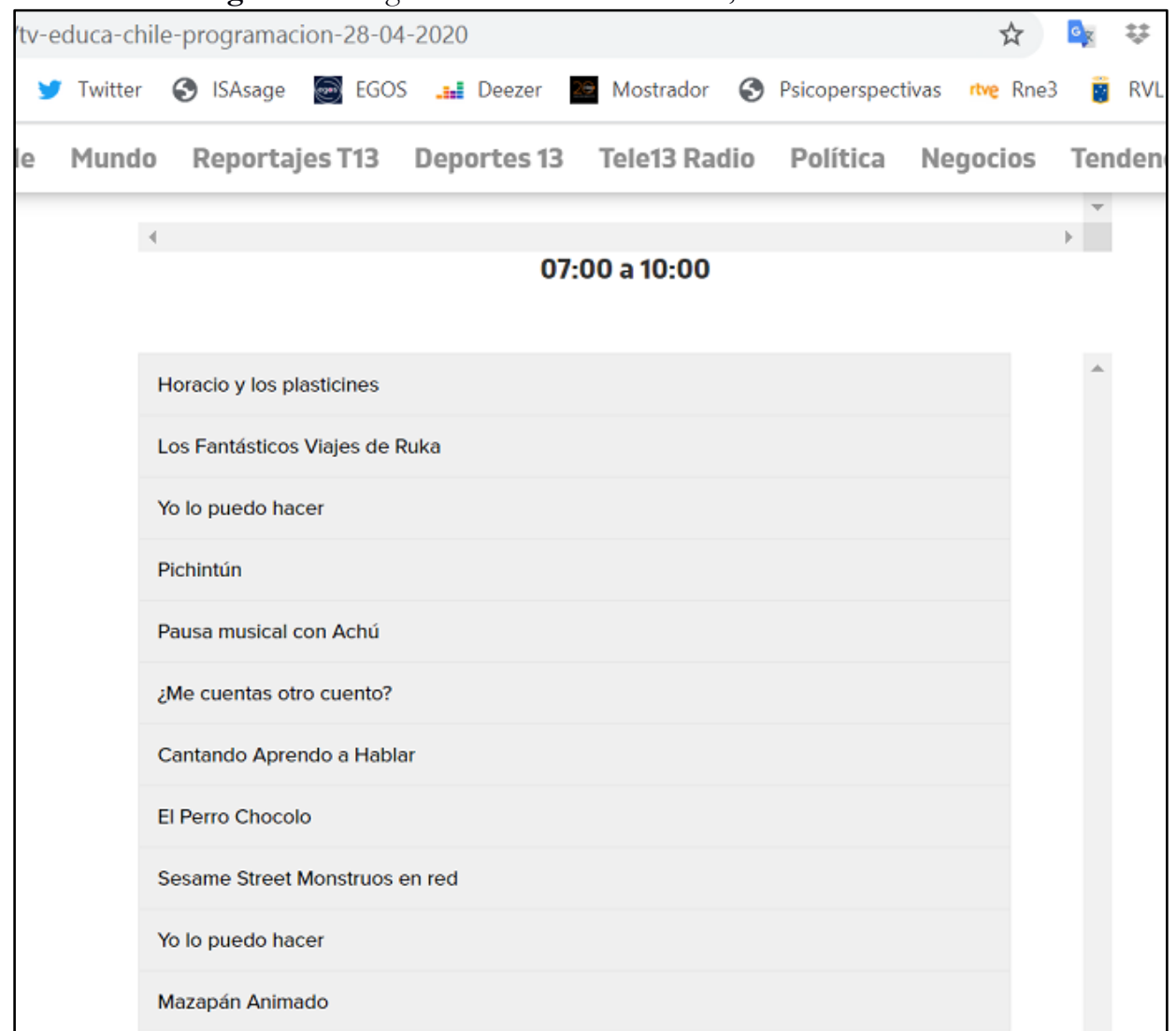

Fuente: https://www.t13.cl/noticia/nacional/tv-educa-chile-programacion-28-04-2020

Así también desde los primeros días de mayo se subieron a un canal de YouTube algunos videos breves que acompañan los módulos de clase. Los que están vinculadas directamente a la página aprendoenlinea.mineduc.cl son lecturas de instrucciones referentes a las actividades contenidas en las correspondientes guías $p d f$ (ver, por ejemplo https://www.youtube.com/watch?v=4qMp5fYiMM). Desde el 8 de mayo aproximadamente se subieron, además, algunos módulos didácticos breves con animadoras y animadores dedicados, sobre todo, a los niveles menores.

En términos generales, como hemos podido observar, y como se indica en la alocución del Ministro Figueroa del 17/03/2020, son los estudiantes, los apoderados y los profesores los responsables por llevar adelante los aprendizajes de las y los estudiantes.

Para asegurar su cumplimiento obviamente se procederá a evaluar. El 12 de mayo se anuncia que el 2020 sí se aplicará el SIMCE, se indica que no tendrá consecuencias sobre las escuelas. Es necesario hacer modificaciones legales, para que eso sea así, y aun no hay proyectos al respecto. Será de carácter censal, es decir, como se hace cada año:

En situaciones de crisis, como la actual emergencia sanitaria, se vuelven especialmente útiles y fundamentales los datos del sistema educacional y la evaluación de los aprendizajes de los estudiantes que se han levantado sistemáticamente. Tener datos hoy hace la diferencia para enfrentar la contingencia y el futuro [...] La crisis del COVID-19 ha obligado a postergar muchas cosas, pero no es el momento de quedarnos a ciegas, menos en el sistema educacional que ha sufrido duramente el embate de esta pandemia. El sistema necesita información válida y confiable como la que entrega el Simce para poder focalizar los esfuerzos en quienes más

Práxis Educativa, Ponta Grossa, v. 15, e2015777, p. 1-26, 2020 Disponível em: <https://www.revistas2.uepg.br/index.php/praxiseducativa $>$ 
lo necesitan (DANIEL RODRÍGUEZ, secretario ejecutivo de la Agencia de Calidad de la Educación, institución a cargo del Simce. 12 de mayo)

Ante la solicitud de suspender o eliminar la prueba SIMCE, al menos para este año, realizada por diversos actores, entre ellos el gremio de profesores, académicos e incluso la mesa de expertos en educación que convocó el propio gobierno ${ }^{4}$, éste responde con lo que Potter (1998) ha denominado retórica ofensiva, orientada a socavar versiones alternativas a la que se busca defender. En efecto el 'quedarnos a ciegas' sirve como recurso para descalificar la posibilidad de no aplicar el instrumento. La reificación del SIMCE como el único dato posible, obviando la tradición diagnóstica y evaluativa que caracteriza la propia formación pedagógica y lo que pueden hacer las comunidades al respecto, produciendo información situada, como han recomendado expertos. Pero no, la única información válida y confiable posible es la del SIMCE, la única que permite enfrentar la contingencia y el futuro y así focalizar los esfuerzos en quienes más lo necesitan.

\section{Conclusiones: E1 Estado evaluador y el abandono de la escuela}

El viernes 15 de mayo de 2020, el Ministerio de Educación emite una priorización curricular, listando los contenidos que serán medidos en la versión 2020 del SIMCE ${ }^{5}$. Nuevamente son los profesores, directivos, apoderados y estudiantes quienes deben hacerse cargo de estos contenidos, ante la ausencia de un sistema educativo que dé soporte en tiempos de crisis. Unas guías $p d f$, un canal de TV con Plaza Sésamo y dibujos animados, y la evaluación con la cual se producirá un ranking de establecimientos. Un ranking que será un ranking de pobreza, de capital social, de conectividad, entre otros. Poco dirá del trabajo de la escuela. Sin embargo, el mandamiento managerial de gobernar por medio de sistemas de evaluación basados en estándares y resultados es religión. Y ante la religión se acata. Es un acto de fe, contra toda la evidencia disponible.

En efecto, la investigación empírica acerca del desempeño de este tipo políticas tiende fuertemente a coincidir en los mismos resultados: estas políticas tienden a concentrar el trabajo de la escuela en el rendimiento en los tests, esto que, potencialmente podría mejorar la enseñanza en áreas claves del currículum, tiende, por el contrario, a reducir el proceso educativo a entrenamiento para los tests, centrando gran parte de los esfuerzos de profesores y la administración en estos rendimientos (POLESEL et al., 2013; SUPOVITZ, 2009). En el ámbito profesional se instaura una cultura de la competitividad que ha conllevado la erosión de la solidaridad y el aumento de la individualización debido a la rendición de cuentas de altas consecuencias (BALL, 2003). Asimismo, diversas investigaciones han mostrado efectos adversos para la escuela, los estudiantes y para el trabajo docente: deserción escolar, debilitamiento de los lazos sociales y comunitarios al interior de la escuela entre los distintos actores, aumento de la conflictividad al interior de la escuela, explicable por la presión de la rendición de cuentas y sus consecuencias, estrés y aumento del malestar, pérdida de sentido del trabajo, entre muchos otros (GARVER, 2019; HOLLOWAY; BRASS, 2017; JENNINGS, 2010; LITTLE; BARTLETT, 2010; OZGA, 2009; RANSON, 2003). Esto, especialmente en los contextos de mayor vulnerabilidad, contextos que supuestamente debiesen ser el foco de la política. Por lo tanto, en un contexto de crisis, como lo supone la pandemia COVID19, esto puede resultar extremo.

\footnotetext{
4 Ver Propuestas sobre Educación Trabajo Interuniversitario Mesa Social Covid-19 en https://www.uchile.cl/documentos/propuestas-sobre-educacion-mesa-social-covid-19_163074_0_4342.pdf

${ }^{5}$ https://curriculumnacional.mineduc.cl/614/articles-177739_archivo_01.pdf
} 
Pero la religión manda. Y son unos los que deciden, evalúan, juzgan, y otros los que no les queda otra que acatar.

Chile, señalado como uno de los principales modelos de gestión educativa exitosa, desde el modelo del Nuevo Management Público, he aquí su prueba crítica: La Escuela, sola, constituida como única responsable por los aprendizajes de los estudiantes, abandonada, evaluada, confinada en el managerialismo.

\section{Epílogo}

El 2 de junio las diputadas y los diputados de oposición González, Vallejo, Rojas y Santana presentaron una moción parlamentaria orientada a suspender la aplicación de la Evaluación Docente y de las pruebas del Sistema de Medición de la Calidad de la Educación (Simce), correspondientes al año 2020, debido a la pandemia de Covid-19 (Moción No 13.554). Esta moción se basó en diversos informes de centros de investigación, entre ellos el Centro de Investigación para la Educación Inclusiva, que justificaban la necesidad de suspender las principales evaluaciones con consecuencias que regulan el sistema, y en las demandas en dicho sentido de agrupaciones de trabajadores de la educación, especialmente el Colegio de Profesores -principal organización sindical docente-, comunidades educativas, y autoridades municipales. Ante el rápido avance del proyecto en el parlamento, el 17 de junio la Agencia de Educación decide suspender el SIMCE por el 2020. Sin embargo, la evaluación docente se mantiene en pie siendo defendida por las autoridades de gobierno persistentemente. Finalmente, el 7 de octubre es promulgada la Ley $\mathrm{N}^{\circ} 21.272$ originada en esta moción parlamentaria, que suspende la evaluación docente por el año 2020, consiguiendo amplio apoyo incluso de parlamentarios de gobierno. En esta aprobación fue especialmente relevante la acción del sindicato docente, de las comunidades educativas y de la investigación empírica que daban cuenta de la poca pertinencia de dicha evaluación. Como investigador, me correspondió colaborar con las agrupaciones de trabajadores y presentar ante el Congreso Nacional un análisis, basado en evidencia empírica, del proyecto de Ley. Si bien en este tiempo el Ministerio no generó mayores apoyos para la práctica educativa en tiempos de pandemia, sí se logró la suspensión de los dos principales instrumentos de rendición de cuentas con altas consecuencias, mostrando que la investigación empírica rigurosa y crítica, articulada con los actores sociales que construyen día a día la educación pública, puede ser una herramienta fundamental para contener y transformar este orden dogmático de la rendición de cuentas con altas consecuencias que se nos impone como verdad incuestionable.

\section{Referencias}

AGGERI, F.; LABATUT, J. Looking at management through its instruments: a genealogical analysis of instrument-based approaches of management. Hal Archives (online), Working Paper 2011, out. 2020. Disponible en: https:// hal.archives-ouvertes.fr/hal-00639734. Acceso en: 28 oct 2020.

ASSAEL, J. et al. Transformaciones en la cultura escolar en el marco de la implementación de políticas de accountability en Chile: Un estudio etnográfico en dos escuelas clasificadas en recuperación. Estudios Pedagógicos, Valdivia, v. 40, n. 2, p. 7-26, out. 2014. DOI: http://dx.doi.org/10.4067/S0718-07052014000300001

Práxis Educativa, Ponta Grossa, v. 15, e2015777, p. 1-26, 2020

Disponível em: <https://www.revistas2.uepg.br/index.php/praxiseducativa $>$ 
ASSAÉL, J. et al. La empresa educativa chilena. Educação \& Sociedade, Campinas, v. 32, n. 115, p. 305-322, abr./jun. 2011. DOI: http://doi.org/10.1590/S0101-73302011000200004

BALL, S. J. The teacher's soul and the terrors of performativity. Journal of Education Policy, London, v. 18, n. 2, 215-228, may. 2003. DOI: https://doi.org/10.1080/0268093022000043065

BAUDOT, P. Le temps des instruments: Pour une socio-histoire des instruments d'action publique. In: HALPERN, C.; LASCOUMES, P.; LE GALÈS, P. (Eds.), P. L'instrumentation de l'action publique: Controverses, résistance, effets. Paris: Presses de Sciences Po, 2014, p. 193-236.

BELLEI, C.; CABALIN, C.; ORELLANA, V. The 2011 Chilean student movement against neoliberal educational policies. Studies in Higher Education, London: Society for Research into Higher Education, v. 39, n. 3, p. 426-440, mar. 2014. DOI: https://doi.org/10.1080/03075079.2014.896179

BLANCO, C. et al. Reconstructing the question of school choice: Towards a geographical agent-based model for Chile. In: MIGUEL, F. J. et al. (orgs.). Advances in Computational Social Science and Social Simulation. Bellaterra, Cerdanyola del Vallès, 2014. p. 381-399.

BRUNS, B.; FILMER, D.; PATRINOS, H. A. Making schools work: New evidence on accountability reforms. Human Development Perspectives, Washington: World Bank Group, fev. 2011. DOI: http://doi.org/10.1596/978-0-8213-8679-8

BRUNS, B.; LUQUE, J. Great Teachers: how to raise student learning in Latin America and the Caribbean. Washington: Banco Mundial, 2014. DOI: https://doi.org/10.1596/978-1-4648-0151-8

CANALS, C. Choice System en Chile: determinantes del cambio de escuela. Calidad en la Educación, Santiago, Chile, n. 45, p. 174-206, dez. 2016. DOI: http://dx.doi.org/10.4067/S0718$\underline{45652016000200006}$

CHATELAIN-PONROY, S. et al. Is commitment to performance- based management compatible with commitment to university "Publicness"? Academics' values in French universities. Organization Studies, Brussels, v. 39, n. 10, p. 1377-1401, out. 2018. DOI: http://doi.org/10.1177/0170840617717099

CHILE. Ministerio de Educación. Ley que Establece Ley de Subvención Escolar Preferencial (Ley No. 20.248). Santiago: Ministerio de Educación, 2008.

CHILE. Ministerio de Educación. Ley General de Educación (Ley No. 20.370). Santiago: Ministerio de Educación, 2009.

CHILE. Ministerio de Educación. Ley que Crea el Sistema de Aseguramiento de Calidad (Ley No. 20.529). Santiago: Ministerio de Educación, 2011.

CHILE. Ministerio de Educación. Resumen estadístico de la Educación 2019. Santiago, Chile: MINEDUC, Centro de Estudios, 2020. 
COX, C.; MECKES, L. International large-scale assessment studies and educational policy-making in Chile: Contexts and dimensions of influence. Research Papers in Education, v. 31, n. 5, p. 502-515, out. 2016. DOI: https://doi.org/10.1080/02671522.2016.1225349

FALABELLA, A. El mercado escolar en Chile y el surgimiento de la nueva gestión pública: El tejido de la política entre la dictadura neoliberal y los gobiernos de la centroizquierda (1979 a 2009). Educação \& Sociedade, Campinas, v. 36, n. 132, p. 699-722, set. 2015. DOI: https://doi.org/10.1590/ES0101-73302015152420

FALABELLA, A.; DE LA VEGA, L. F. Políticas de responsabilización por desempeño escolar: Un debate a partir de la literatura internacional y el caso chileno. Estudios Pedagógicos, Valdivia, v. 42, n. 2, p. 395-413, dez. 2016. DOI: http://dx.doi.org/10.4067/S0718-07052016000200023

GARVER, R. Evaluative relationships: Teacher accountability and professional culture professional culture. Journal of Education Policy, v. 35, n. 5, p. 623-647, jan. 2019. DOI: http://doi.org/10.1080/02680939.2019.1566972

GUNTER, H. M. Policy and workforce reform in England. Educational Management Administration \& Leadership, v. 36, n. 2, p. 253-270, abr. 2008. DOI: http://doi.org/10.1177/1741143207087776

HALL, D.; GUNTER, H. M.; SERPIERI, R. Educational reform and modernisation in Europe: the role of national contexts in mediating the new public management. European Educational Research Journal, v. 14, n. 6, p. 487-507, nov. 2015. DOI: http://doi.org/10.1177/1474904115615357

HENMAN, P. Performing the state: The socio-political dimensions of performance measurement in policy and public services. Policy Studies, v. 37, n. 6, p. 499-507, set. 2016. DOI https://doi.org/10.1080/01442872.2016.1144739

HOLLOWAY, J.; BRASS, J. Making accountable teachers: The terrors and pleasures of performativity. Journal of Education Policy, London, v. 9, n. 39, p. 361-382, set. 2017. DOI: http://doi.org/10.1080/02680939.2017.1372636

HOLZINGER, K.; SCHMIDT, S. From the Positive to the Regulatory State : A Transformation in the Machinery of Governance? In Leibfried, S.; Huber, E.; Lange, M.; Levy, J.; Stephens, J. (Eds.), The Oxford Handbook of Transformations of the State. Oxford: Oxford University Press, 2015. p. 499-515. DOI: https://dx.doi.org/10.1093/oxfordhb/9780199691586.013.26

HOOD, C. A public management for all seasons? Public Administration, Hoboken, v. 69, n. 1, p. 319, mar. 1991. DOI: https://doi.org/10.1111/j.1467-9299.1991.tb00779.x

GAO, J. Performance measurement and management in the public sector: some lessons from research evidence. Public Administration and Development, v. 35 n. 2, p. 86-96, jun. 2015. DOI: https://doi.org/10.1002/pad.1704

IÑÍGUEZ, L. (Ed.). Análisis del Discurso: Manual para las ciencias sociales. Barcelona: UOC, 2006. 
JENNINGS, J. L. School choice or schools' choice?: Managing in an Era of Accountability. Sociology of Education, v. 83, n. 3, p. 227-247, jul. 2010. DOI: https://doi.org/10.1177/0038040710375688

KERR, A.; CUNNINGHAM-BURLEY, S.; TUTTON, R.. Shifting subject positions: Experts and lay people in public dialogue. Social Studies of Science, v. 37, n. 3, p. 38, jun. 2007. DOI: http://doi.org/10.1177/00380407103756885-411

KURUNMÄKI, L.; MILLER, P. Regulatory hybrids: Partnerships, budgeting and modernising government. Management Accounting Research, v. 22, n. 4, p. 220-241, dez. 2011. DOI: http://doi.org/10.1016/j.mar.2010.08.004

LE GALÈS, P. Policy instruments and governance (2010). In: M. BEVIR (Ed), The SAGE Handbook of Governance. London: SAGE Publications, 2011. p. 1-18. DOI: http://dx.doi.org/10.4135/9781446200964.n10

LE GALÈS, P. Performance measurement as a policy instrument. Policy Studies, v. 37, n. 6, p. 508520, set. 2016. DOI: http://doi.org/10.1080/01442872.2016.1213803

LITTLE, J. W.; BARTLETT, L. The Teacher Workforce and Problems of Educational Equity. Review of Research in Education, v. 4, n. 1, p. 285-328, mar. 2010. DOI: http://doi.org/10.3102/0091732X09356099

LÓPEZ, V.; ORTIZ, S.; ALBURQUERQUE, F. La judicialización de la convivencia escolar en el marco del Sistema de Aseguramiento de la Calidad de la Educación chileno: El caso de las denuncias escolares. Práxis Educativa, Ponta Grossa, v. 15, e2015452, p. 1-22, jul. 2020. DOI: https://doi.org/10.5212/PraxEduc.v.15.15452.075

MCEWAN, P. J.; CARNOY, M. The effectiveness and efficiency of private schools in Chile's voucher system. Educational Evaluation and Policy Analysis, v. 22, n. 3, p. 213-239, jan. 2000. DOI: https://doi.org/10.3102/01623737022003213

MILLER, P.; O'LEARY, T. Mediating instruments and making markets: Capital budgeting, science and the economy. Accounting, Organizations and Society, v. 32, n. 7-8, p. 701-734. out./ nov. 2007. DOI: http://doi.org/10.1016/j.aos.2007.02.003

MIZALA, A.; SCHNEIDER, B. Promoting quality education in Chile: The politics of reforming teacher careers. Journal of Education Policy, v. 35, p. 529-555, mar. 2019. DOI: https://doi.org/10.1080/02680939.2019.1585577

MONTECINOS, C.; SISTO, V.; AHUMADA, L. The construction of parents and teachers as agents for the improvement of municipal schools in Chile. Comparative Educaction, v. 46, n. 4, p. 487508, nov. 2010. https://doi.org/10.1080/03050068.2010.519481

MURNANE, R.; PAGE, L.; VEGAS, E. Distribution of student achievements in Chile: Baseline analysis for the evaluation of the Subvention Escolar Preferencial, SEP (Preferential School Subsidy). Washington; World Bank Group, 2009. Disponível em: http://documents1.worldbank.org/curated/en/233391468014979699/pdf/702910ESW0P1110Base line0Paper0Final.pdf Acceso en: 7 mayo 2020. 
OCDE. Chile. Revisión de las políticas Nacionales de Educación. París: Organización para la Cooperación y el Desarrollo, 2004.

OSBORNE, D.; GAEBLER. T. Reinventing Government: How the Entrepreneurial Spirit Is Transforming the Public Sector. New York: Addison-Wesley Publishing Co., 1992.

OYARZÚN, C.; CORNEJO, R. Trabajo docente y nueva gestión pública en chile: una revisión de la evidencia. Educação \& Sociedade, Campinas, v. 41, e219509, May., 2020. https://doi.org/10.1590/es.219509

OYARZÚN-MALDONADO, C.; SOTO-GONZÁLEZ, R. I. Subvención escolar preferencial en Chile: ¿Descentralización focalizada para el mejoramiento escolar? International Journal of Sociology of Education, Barcelona, v. 7, n. 2, 181-208, Jun., 2018. DOI: https://doi.org/10.17583/rise.2018.3321

OZGA, J. Governing education through data in England: From regulation to self-evaluation. Journal of Education Policy, London, v. 24, n. 2, p. 149-162, mar. 2009. DOI: http://doi.org/10.1080/02680930902733121

PEREIRA, M. Continuidade, ruptura ou reciclagem? Uma análise do programa político do Banco Mundial após o Consenso de Washington. Dados, Rio de Janeiro, v. 58, n. 2, p. 461-498, abr./jun. 2015. DOI: $\underline{\text { http://dx.doi.org/10.1590/00115258201550 }}$

POLESEL, J.; RICE, S.; DULFER, N. The impact of high-stakes testing on curriculum and pedagogy : A teacher perspective from Australia. Journal of Education Policy, v. 29, n. 5, p. 640-657, set. 2014. DOI: http://doi.org/10.1080/02680939.2013.865082

PORTALES, J.; VAZQUEZ-HEILIG, J. Understanding how universal vouchers have impacted urban school districts' enrollment in Chile. Education Policy Analysis Archives, v. 22, p. 72, 2014. DOI: http://dx.doi.org/10.14507/epaa.v22n72.2014

POTTER, J. La representación de la realidad: Discurso, retõrica y construcciõn social. Barcelona: Paidós, 1998.

POTTTER, J.; WETHERELL, M. Discourse and social psychology: Beyond attitudes and behaviour. Newbury Park,: Sage Publications, 1987.

PRIOR, L. Repositioning documents in social research. Sociology, v. 42, n. 5, p. 821-836, 2008. DOI: https://doi.org/10.1177/0038038508094564

PRIOR, L. Using Documents in Social Research. In: SILVERMAN, D. (Ed.). Qualitative Research. Sage, London, 2016

QUARESMA, M. L.; VALENZUELA, J. P. Evaluation and accountability in large-scale educational system in Chile and its effects on student's performance in urban schools. In: PINK W., NOBLIT, G. (Eds.), Second International Handbook of Urban Education. Springer, Cham.: Springer 
International Handbooks of Education, 2017. DOI: https://doi.org/10.1007/978-3-319-40317-5 29

RAMÍREZ, L.; BALERIOLA, E.; SISTO, V. Pedagogía na era da responsabilidade: Análise do portfólio de ensino no Chile. Educação \& Sociedade, Campinas, v. 40, e0209826, p. 1-20, set. 2019, http://dx.doi.org/10.1590/es0101-73302019209826

RANSON, S. Public accountability in the age of neo-liberal governance. Journal of Education Policy, v. 18, n. 5, p. 459-480, 2003. DOI: http://doi.org/10.1080/0268093032000124848

RICH, A. Think tanks, public policy, and the politics of expertise. New York: Cambridge University Press, 2004.

SELBERG, R. Nursing in times of neoliberal change: An ethnographic study of nurses' experiences of work intensification. Nordic Journal of Working Life Studies, v. 3, n. 2, p. 9-36, maio. 2013. DOI: https://doi.org/10.19154/njwls.v3i2.2548

SHAH, A. M. Public Services Delivery, Washington, D. C.: World Bank, 2005. DOI: https://doi.org/10.1177/097215090500600208

SHORE, C.; WRIGHT, S. Governing by numbers: Audit culture, rankings and the new world order. Social Anthropology, v. 23, n. 1, p. 22-28, fev., 2015. DOI: http://doi.org/10.1111/1469-8676.12098

SISTO, V. Teorías organizacionales postmodernas y la gestación del sujeto postmoderno. Psicología de la Salud y de la Psicología Social. Athenea Digital. Revista de pensamiento e investigación social, v. 1, n. 6, nov. 2004. DOI: https://doi.org/10.5565/rev/athenead/v1n6.176

SISTO, V. Identidades desafiadas: Individualización, managerialismo y trabajo docente en el Chile actual. Psykhe, Santiago, v. 21, n. 2, p. 35-46, nov. 2012. DOI: http://dx.doi.org/10.7764/psykhe.21.2.542

SISTO, V. Gobernados por números: El financiamiento como forma de gobierno de la universidad en Chile. Psicoperspectivas, Valparaíso, v. 16, n. 3, p. 64-75, nov., 2017. DOI: https://dx.doi.org/10.5027/psicoperspectivas-vol16-issue3-fulltext-1230

SISTO, V. Managerialismo, autoritarismo y la lucha por el alma de la gestión: El caso de las últimas reformas en políticas de dirección escolar en Chile. Revista da FAEEBA-Educação e Contemporaneidade, v. 27, n. 53, p. 141-156, dez. 2018. DOI: https://doi.org/10.21879/faeeba2358-0194.2018.v27.n53.p141-156

SISTO, V. Inclusion "in the Chilean way": School inclusion in a context of advanced neoliberal policies. Education Policy Analysis Archives, n. 27, p. 1-23, mar. 2019a. DOI: http://dx.doi.org/10.14507/epaa.27.3044

SISTO, V. Managerialismo versus prácticas locales: La decolonización del discurso managerial desde la vida de la Escuela. Cuadernos de Administración, v. 32, n. 58, jun., 2019b. DOI: https://doi.org/10.11144/Javeriana.cao32-58.mvpl

SISTO, V. Desbordadas/os: Rendición de Cuentas e Intensificación del Trabajo en la Universidad 
Neoliberal. El Caso de Chile. Education Policy Analysis Archives, n. 28, p. 1-26, ene 2020. DOI: https://doi.org/10.14507/epaa.28.4907

SISTO, V.; FARDELLA, C. Nuevas Políticas Públicas, epocalismo e identidad: El caso de las políticas orientadas a los docentes en Chile. Revista de Estudios Universitarios, Sorocaba, v. 37, n. 1, p. 123141, jun. 2011.

SISTO, V.; FARDELLA, C. El eclipse del profesionalismo en la era de la rendición de cuentasModelando docentes en el contexto del nuevo management público. Cadernos de Educação, Pelotas, n. 49, p. 3-23, 2014. DOI: https://doi.org/10.15210/caduc.v0i49.5580

SISTO, V.; MONTECINOS, C.; AHUMADA, L. Disputas de significado e identidad: La construcción local del trabajo docente en el contexto de las políticas de evaluación e incentivo al desempeño en Chile. Universitas Psychologica, Bogotá, v. 12, n. 1, p. 173-184, maio, 2013. DOI: https://doi.org/10.11144/Javeriana.upsy12-1.dsic

SISTO, V.; ZELAYA, V. La etnografía de dispositivos como herramienta de análisis y el estudio del managerialismo como práctica local. Universitas Psychologica, Bogotá, v. 12, n. 4, p. 1345-1354, ago. 2013. DOI: https://doi.org/10.11144/Javeriana.UPSY12-4.edha

SO, S. et al. Alternative paths to public financial management and public sector reform: Experiences from East Asia. Washington, D. C.: World Bank, 2018 https://doi.org/10.1596/978-1$\underline{4648-1316-0}$

SUPOVITZ, J. Can high stakes testing leverage educational improvement? Prospects from the last decade of testing and accountability reform. Journal of Educational Change, v. 10, p. 211-227, maio, 2009. DOI: http://doi.org/10.1007/s10833-009-9105-2

VALLI, L.; BUESE, D. The changing roles of teachers in an era of high-stakes accountability. v. 44, n. 3, p. 519-558, set. 2007. DOI: https://doi.org/10.3102/0002831207306859

VEGAS, E.; GANIMIAN, A. What are the teacher policies of top-performing and rapidlyimproving education systems? Washington, D. C: World Bank Human Development Network 2011. Disponible en: https://bit.ly/2VnsM0z. Acceso em: 20 oct. 2020.

VERBEETEN, F. H. M; SPEKLÉ, R. F. Management control, results-oriented culture and public sector performance : Empirical evidence on new public management. Organization Studies, v. 36, n. 7, p. 953-978, abr. 2015. DOI: http://doi.org/10.1177/0170840615580014

VERGER, A. Framing and selling global education policy: The promotion of public-private partnerships for education in low-income contexts. Journal of Education Policy, v. 27, n. 1, p. 109130, jan./fev. 2012. DOI: http://doi.org/10.1080/02680939.2011.623242

VERGER, A.; NORMAND, R. Nueva gestión pública y educación: elementos teóricos y conceptuales para el estudio de un modelo de reforma educativa global. Educação \& Sociedade, v. 36, n. 132, p. 599-622, jul./set., 2015. DOI: https://doi.org/10.1590/ES0101-73302015152799

VILLALOBOS, C.; QUARESMA, M. L. Sistema escolar chileno: Características y consecuencias de

Práxis Educativa, Ponta Grossa, v. 15, e2015777, p. 1-26, 2020

Disponível em: <https://www.revistas2.uepg.br/index.php/praxiseducativa $>$ 
un modelo orientado al mercado. Convergencia, Toluca, n. 69, p. 63-84, set./dez. 2015. DOI: https://doi.org/10.29101/crcs.v22i69.3634

WATANABE, M. Displaced teacher and state priorities in a high-stakes accountability context. Educational Policy, v. 21, n. 2, p. 311-368, maio, 2007. DOI: http://doi.org/10.1177/0895904805284114

WETHERELL, M. A step too far: Discursive psychology, linguistic ethnography and questions of identity. Journal of Sociolinguistics, v. 11, n. 5, p. 661-681, nov. 2007. DOI: https://doi.org/10.1111/j.1467-9841.2007.00345.x

Recibido: 02/06/2020

Versión corregida recibida: $28 / 11 / 2020$

Aceptado: 29/11/2020

Publicado online: 02/12/2020 